\title{
EFEKTIVITAS PENGGUNAAN MODEL BELAJAR KOPERATIF INSIDE OUTSIDE CIRCLE PADA PEMBELAJARAN KOSAKATA BAHASA INGGRIS SISWA TINGKAT DASAR
}

\author{
Elyza Martiarini ${ }^{1}$ dan Risa Mufliharsi ${ }^{2}$ \\ Program Studi Pendidikan Bahasa Inggris \\ Fakultas Bahasa dan Seni Universitas Indraprasta PGRI \\ Jl. Nangka No. 58, Tanjung Barat, Jakarta Selatan 12530 \\ elyza.martia@gmail.com rsmufliharsi@gmail.com
}

\begin{abstract}
Abstrak
Inside-outside-circle adalah model pembelajaran dimana siswa saling membagi informasi pada saat yang bersamaan, dengan pasangan yang berbeda dengan singkat dan teratur. Adapun informasi yang saling dibagi merupakan isi materi pembelajaran yang mengarah pada tujuan pembelajaran. Pada saat berbagi informasi, maka semua siswa akan saling memberi dan menerima informasi pembelajaran. Tujuan model pembelajaran ini adalah melatih siswa belajar mandiri dan belajar berbicara menyampaikan informasi kepada orang lain, selain itu juga melatih kedisiplinan dan ketertiban. Inside Outside Circle memiliki strategi pencapaian kompetensi peserta didik dengan pendekatan, metode, dan teknik pembelajaran yang efektif dan spesifik yang akan mempengaruhi keberhasilan siswa dalam pembelajaran khususnya Bahasa Inggris demi mewujudkan suatu pembelajaran yang kreatif dan inovatif yang akan diterapkan dalam kegiatan belajar dengan harapan dapat membuat suasana pengajaran bahasa Inggris menjadi kreatif dan inovatif serta para siswa mendapatkan suasana baru dalam belajar dengan menggunakan model yang menyenangkan.
\end{abstract}

Kata kunci: Inside Outside Circle, kosakata bahasa Inggris tingkat dasar

\section{The Effect Of Using Inside Outside Circle Cooperative Learning Model On Students' Basic English Vocabulary Mastery}

\begin{abstract}
Inside Outside Circle is a cooperative learning model in which every single student will share information to one another with different partners in a particular time briefly. Information or knowledge which is shared by student must relate to learning material being discussed and based on the content that lead them to objective of learning. Besides sharing of information, then all students will receive information giving and learning. The purpose of this learning model is to train students to learn independently and to learn conveying information to others, while also to learn practicing self-discipline and order. Inside Outside Circle has a strategy to achieve the competence of learners with the approaches, methods, and techniques of effective learning and specific that will affect student success in learning, especially English in order to realize a creative learning and innovative that will be applied in learning activities with the hope to create an English language teaching atmosphere to be creative and innovative, and the students get a new atmosphere in learning by using a fun model.
\end{abstract}

Keywords: Inside Outside Circle, Basic English Vocabulary

\section{PENDAHULUAN}

Pembelajaran pada tingkat pendidikan dasar memiliki peran penting dari seluruh kegiatan pembelajaran yang akan dialami oleh siswa, karena selain pada saat pendidikan dasar tersebut guru menanamkan nilai moral, nilai-nilai 
agama, sosial emosional, konsep diri, disiplin dan kemandirian serta mengembangkan kemampuan dasar fisik, kognitif, bahasa, dan seni, pada pembelajaran di tingkat dasar disajikan secara tematik yaitu menyajikan pembelajaran secara konkrit tanpa dipilah satu dengan lainnya menjadi bidang-bidang ilmu tertentu. Implikasi dari pembelajaran tematik antara lain adalah guru yang akan menyajikan pembelajaran harus memiliki kreatifitas dalam kegiatan pembelajaran.

\section{Hingar-bingar}

pro-kontra pemberian pelajaran bahasa Inggris di sekolah dasar tidak luput dari pengetahuan sekaligus ketidaktahuan masyarakat luas tentang dasar pemikiran kebijakan pengajaran bahasa Inggris pada tingkat sekolah dasar. Salah satu dasar pemikiran yang lazim diketahui oleh masyarakat luas adalah kebutuhan keterampilan berbahasa Inggris dalam era komunikasi dan globalisasi. Dasar pemikiran ini sangat tidak salah dengan memperhatikan bahwa penguasaan bahasa Inggris sangat diperlukan untuk mentransfer ilmu, baik dalam bahasa Inggris lisan atau tertulis. Kenyataan di dunia saat ini yang menempatkan bahasa Inggris sebagai bahasa yang penting dalam segala bidang kehidupan (sosial, politik, dan ekonomi) mau tak mau harus ditanggapi dengan semakin dikuasainya bahasa tersebut. Namun dasar pemikiran lain yang belum tentu diketahui oleh praktisi pendidikan tingkat sekolah dasar, apalagi masyarakat luas adalah bahwa pengajaran bahasa asing, terutama bahasa Inggris di sekolah dasar sebenarnya untuk mengenalkan kepada siswa bahwa ada bahasa lain selain bahasa ibu. Oleh karena sifatnya hanya untuk perkenalan, seharusnya bahasa Inggris diajarkan melalui kegiatan yang sesuai dengan kegiatan di dunia anakanak, seperti menyanyi, menggambar, bermain, dan bercerita. Bahasa Inggris tidak seyogyanya diajarkan dengan tingkat kesulitan yang melebihi dunia anak kecil, seperti yang diungkapkan oleh Felix dan Schwartz (dalam Haznedar dan Gasruseva, 2008) yang menyampaikan bahwa "Child L2 (second language) learners, unlike L2 adults, are considered to be much more successful in terms of rate of acquisition and ultimate attainment of L2 properties and hence have been argued to have full access to UG (Universal Grammar)".

Namun realita yang ada di lapangan, bahan ajar bahasa Inggris untuk SD cukup banyak di pasaran, namun tidak banyak yang memenuhi syarat untuk dipakai sebagai buku pegangan siswa di kelas. Oleh karena itu, guru harus mampu dan terampil memilih buku dengan mempertimbangkan kesesuaian dengan tujuan, isi, bahasa, dan tingkat kesulitan untuk siswa.

Pengajaran bahasa Inggris di SD telah dilaksanakan dengan berbagai macam kendala dan permasalahannya, berarti anak-anak di Indonesia saat ini belajar bahasa Inggris lebih awal dan mereka lebih lama belajar bahasa Inggris. Oleh karena itu, "rasa senang" siswa belajar bahasa Inggris perlu dipertahankan. Sebagian besar guru yang mengajar bahasa Inggris di SD belum memiliki kemampuan dan keterampilan berbahasa Inggris yang memadai untuk berperan sebagai guru bahasa asing di sekolah dasar karena sebagian besar mereka tidak memiliki latar belakang pendidikan bahasa Inggris.

Sasaran penerapan model pembelajaran koperatif Inside Outside Circle pada pembelajaran kosakata bahasa Inggris tingkat dasar adalah MI (Madrasah Ibtidaiyah) Miftahul Jannah di wilayah Cijantung, Pasar Rebo Jakarta Timur, yang berjumlah 51 orang siswa kelas I, dengan tujuan:

1. Mengenalkan dan menerapkan model pembelajaran koperatif Inside 
Outside Circle pada pembelajaran kosakata bahasa Inggris siswa tingkat dasar,

2. Memotivasi minat belajar bahasa Inggris siswa pada tingkat dasar agar memiliki rasa senang terhadap pembelajaran bahasa kedua,

3. Mengembangkan kemampuan berbahasa siswa pada tingkat dasar yang disertai dengan tindakan agar digunakan dalam interaksi dan bersifat berkaitan dengan hal-hal yang berada dalam konteks situasi,

4. Memberikan dorongan bagi siswa untuk berlatih membuat catatan kosakata bahasa Inggris tingkat dasar,

5. Meningkatkan skor kosakata bahasa Inggris para siswa tingkat dasar karena penyajian pembelajaran ini disajikan dengan interaktif dan menarik.

\section{PEMBAHASAN}

\section{KAJIAN TEORI}

\section{Pembelajaran Koperatif (Cooperatie Learning)}

Model pembelajaran kooperatif adalah rangkaian kegiatan belajar yang dilakukan oleh siswa dalam kelompokkelompok tertentu untuk mencapai tujuan pembelajaran yang telah dirumuskan. Slavin dalam Isjoni (2009: 15) menyatakan bahwa pembelajaran kooperatif adalah suatu model pembelajaran dimana siswa belajar dan bekerja dalam kelompok-kelompok kecil secara kolaboratif yang anggotanya 5 orang dengan struktur kelompok heterogen. Pembelajaran kooperatif adalah model pembelajaran yang berfokus pada penggunaan kelompok kecil siswa untuk bekerja sama dalam memaksimalkan kondisi belajar untuk mencapai tujuan belajar (Sugiyanto, 2010: 37).
Lie (2007: 29) mengungkapkan bahwa model pembelajaran cooperative learning tidak sama dengan sekedar belajar dalam kelompok. Ada lima unsur dasar pembelajaran cooperative learning yang 10 membedakannya dengan pembagian kelompok yang dilakukan asal-asalan. Pelaksanaan model pembelajaran kooperatif dengan benar akan menunjukkan pendidik mengelola kelas lebih efektif.

Dalam kelas kooperatif, para siswa diharapkan dapat saling membantu, saling mendiskusikan, serta berargumentasi untuk mengasah pengetahuan yang mereka kuasai saat itu dan menutup kesenjangan dalam pemahaman masing-masing.

Dari beberapa definisi yang dikemukakan oleh para ahli di atas, maka dapat ditarik kesimpulan bahwa pembelajaran kooperatif adalah model pembelajaran yang menempatkan siswa dalam kelompok-kelompok kecil yang anggotanya bersifat heterogen, terdiri dari siswa dengan prestasi tinggi, sedang, dan rendah, perempuan dan lakilaki dengan latar belakang etnik yang berbeda untuk saling membantu dan bekerja sama mempelajari materi pelajaran agar belajar semua anggota maksimal.

\section{Pembelajaran Inside Outside Circle}

Maufur (2009:101) metode pembelajaran Inside-Outside Circle (lingkaran besar-lingkaran kecil) yang dikembangkan oleh Spencer Kagan pada tahun 1993 ini mengajarkan kemampuan beradaptasi secara cepat dan cermat pada setiap pasangan yang berbeda, yaitu peserta didik saling bertukar informasi pada saat yang bersamaan, dengan pasangan yang berbeda dengan singkat dan teratur.

Metode pembelajaran InsideOutside Circle termasuk dalam pembelajaran kooperatif karena 
mengajarkan kepada peserta didik ketrampilan bekerjasama dan kolaborasi secara berkelompok. Metode ini memberikan peluang kepada anak agar dapat bekerja sama dalam memahami serta menyelesaikan suatu permasalahan.

Menurut Lie (2008:65), teknik pembelajaran Inside Outside Circle adalah teknik pembelajaran yang dikembangkan untuk memberikan kesempatan pada siswa agar saling berbagi informasi pada saat yang bersamaan. Pendekatan ini bisa digunakan dalam beberapa mata pelajaran, seperti: ilmu pengetahuan sosial, agama, matematika, dan bahasa. Bahan pelajaran yang paling cocok digunakan dengan teknik Inside Outside Circle ini adalah bahan yang membutuhkan pertukaran pikiran dan informasi antar siswa.

Keunggulan dari teknik pembelajaran Inside Outside Circle adalah adanya struktur yang jelas dan memungkinkan siswa untuk berbagi dengan pasangan yang berbeda dengan singkat dan teratur. Selain itu, siswa bekerja dengan sesama siswa dalam suasana gotong-royong dan mempunyai banyak kesempatan untuk mengolah informasi dan meningkatkan keterampilan ber-komunikasi. Model Inside Outside Circle ini bisa digunakan untuk semua tingkat usia anak didik.

Penerapan model pembelajaran IOC terbukti dapat meningkatkan perhatian dan konsentrasi siswa. Seperti yang dikemukakan Dimyati dan Mudjiono (2006:4) belajar merupakan pengalaman yang diperoleh dari lingkungan. Pengalaman pada dasarnya adalah hasil dari interaksi antara siswa dengan lingkungannya. Menghadirkan nuansa pembelajaran yang menarik dapat meningkatkan hasil belajar siswa. Pembelajaran kooperatif model IOC merupakan salah satu jenis pembelajaran kooperatif yang cukup menarik untuk diterapkan (Suprijono, 2011:97). Lebih lanjut Isjoni (2011:61) menyatakan bahwa menciptakan lingkungan kelas yang menarik maka dapat memudahkan siswa dalam memahami materi.

\section{Materi dan Metode Pelaksanaan Kegiatan Penerapan IOC}

1. Pada setiap pertemuan, tim menjelaskan tujuan pembelajaran/ KD mengenai kosakata bahasa Inggris kepada para siswa.

2. Siswa dibagi menjadi beberapa kelompok beranggotakan 3-4 orang.

3. Tiap-tiap kelompok mendapat tugas mencari informasi berdasarkan pembagian tugas dari guru (misal : toys, colors, animals, dsb).

4. Setiap kelompok belajar mandiri, mencari informasi berdasarkan tugas yang diberikan kemudian mencatat kosakata yang telah mereka dapat pada catatan yang diberikan oleh guru.

5. Setelah selesai, maka seluruh siswa berkumpul saling membaur (tidak berdasarkan kelompok).

6. Separuh kelas lalu berdiri membentuk lingkaran kecil dan menghadap keluar.

7. Separuh kelas lainnya membentuk lingkaran di luar lingkaran pertama, menghadap ke dalam.

8. Dua siswa yang berpasangan dari lingkaran kecil dan besar berbagi informasi. Pertukaran informasi ini bisa dilakukan oleh semua pasangan dalam waktu yang bersamaan.

9. Kemudian siswa berada di lingkaran kecil diam di tempat, sementara siswa yang berada di lingkaran besar bergeser satu atau dua langkah searah jarum jam.

10. Selanjutnya giliran siswa berada di lingkaran besar yang membagi informasi. Demikian seterusnya, sampai seluruh siswa selesai berbagi 
informasi. Pada setiap akhir pertemuan, tim menentukan waktu pembebelajaran apabila jam pelajaran tidak cukup waktu.

\section{Hambatan}

Pengajaran bahasa Inggris di SD telah dilaksanakan dengan berbagai macam kendala dan permasalahannya. Oleh karena itu, "rasa senang" siswa belajar bahasa Inggris perlu dipertahankan. Realita yang ada di lapangan, sebagian besar guru yang mengajar bahasa Inggris di MI Miftahul Jannah belum memiliki kemampuan dan keterampilan berbahasa Inggris yang memadai untuk berperan sebagai guru bahasa asing di tingkat dasar karena sebagian besar mereka tidak memiliki latar belakang pendidikan bahasa Inggris. Selain itu, bahan ajar bahasa Inggris untuk SD cukup banyak di pasaran, namun tidak banyak yang memenuhi syarat untuk dipakai sebagai buku pegangan siswa di kelas. Oleh karena itu, guru harus mampu dan terampil memilih buku dengan mempertimbangkan kesesuaian dengan tujuan, isi, bahasa, dan tingkat kesulitan untuk siswa.

\section{Solusi}

Melihat permasalahan yang ada di lapangan, tim tergerak untuk melakukan sebuah kegiatan penerapan model pembelajaran Inside-Outside Circle pada kosakata bahasa Inggris siswa tingkat dasar di MI Miftahul Jannah Cijantung, Jakarta Timur. Kegiatan penerapan pembelajaran menggunakan model belajar Inside Outside Circle ini belum pernah digunakan oleh pihak sekolah sebelumnya dalam pencapaian belajar kosakata bahasa Inggris.

Agar kualitas pembelajaran kosakata bahasa Inggris tingkat dasar meningkat, hal yang dilakukan antara lain; (1) membuat students' notebook,
(2) menyiapkan rencana atau rancangan pembelajaran menggunakan model pembelajaran Inside Ooutside Circle dengan memperhatikan pembagian waktu yang sebaik-baiknya, menambahkan waktu dalam pelaksanaan IOC, dan (4) mempersiapkan ulang lembar observasi pengelolaan pembelajaran guru, lembar observasi aktivitas siswa, dan lembar catatan lapangan.

\section{Hasil yang Dicapai}

Dari pelaksanaan kegiatan yang telah dilaksanakan di MI Miftahul Jannah, diperoleh data sebagai berikut:

Dari pretes kosakata yang diberikan oleh tim dapat digambarkan dalam tabel berikut:

\begin{tabular}{|c|c|c|c|c|}
\hline No. & Siswa & $\begin{array}{c}\text { Jenis } \\
\text { Kelamin }\end{array}$ & Pre tes & Post Tes \\
\hline 1 & AA & $\mathrm{P}$ & 45 & 50 \\
\hline 2 & $\mathrm{AB}$ & $\mathrm{L}$ & 45 & 75 \\
\hline 3 & $\mathrm{AC}$ & $\mathrm{P}$ & 35 & 60 \\
\hline 4 & $\mathrm{AD}$ & $\mathrm{P}$ & 45 & 65 \\
\hline 5 & $\mathrm{AE}$ & $\mathrm{P}$ & 45 & 65 \\
\hline 6 & $\mathrm{AF}$ & $P$ & 60 & 80 \\
\hline 7 & $\mathrm{BN}$ & $\mathrm{P}$ & 70 & 75 \\
\hline 8 & $\mathrm{DZ}$ & $\mathrm{P}$ & 55 & 55 \\
\hline 9 & GN & $P$ & 55 & 50 \\
\hline 10 & IK & $\mathrm{P}$ & 65 & 80 \\
\hline 11 & LM & $\mathrm{P}$ & 45 & 65 \\
\hline 12 & MA & $\mathrm{L}$ & 40 & 75 \\
\hline 13 & MI & $\mathrm{L}$ & 70 & 55 \\
\hline 14 & MR & $\mathrm{L}$ & 80 & 90 \\
\hline 15 & $\mathrm{PZ}$ & $\mathrm{P}$ & 60 & 85 \\
\hline 16 & MK & $\mathrm{P}$ & 65 & 65 \\
\hline 17 & $\mathrm{RF}$ & $\mathrm{L}$ & 40 & 65 \\
\hline 18 & $\mathrm{RU}$ & $\mathrm{P}$ & 65 & 80 \\
\hline 19 & RA & L & 45 & 75 \\
\hline 20 & $\mathrm{RE}$ & $\mathrm{L}$ & 50 & 55 \\
\hline 21 & $\mathrm{RH}$ & $\mathrm{L}$ & 65 & 65 \\
\hline 22 & $\mathrm{RN}$ & $P$ & 60 & 65 \\
\hline 23 & SA & $\mathrm{L}$ & 35 & 75 \\
\hline 24 & VT & $\mathrm{P}$ & 50 & 60 \\
\hline 25 & Z & $\mathrm{L}$ & 75 & 85 \\
\hline 26 & $\mathrm{AS}$ & $\mathrm{P}$ & 60 & 85 \\
\hline 27 & $\mathrm{AG}$ & $\mathrm{P}$ & 85 & 90 \\
\hline 28 & $\mathrm{AN}$ & $\mathrm{P}$ & 70 & 80 \\
\hline 29 & $\mathrm{AR}$ & $\mathrm{P}$ & 50 & 80 \\
\hline 30 & $\mathrm{AK}$ & $\mathrm{P}$ & 65 & 60 \\
\hline 31 & $\mathrm{BA}$ & $P$ & 40 & 60 \\
\hline 32 & $\mathrm{DM}$ & $\mathrm{P}$ & 65 & 65 \\
\hline 33 & DD & $\mathrm{P}$ & 70 & 85 \\
\hline 34 & DT & $\mathrm{L}$ & 55 & 65 \\
\hline 35 & FA & $\mathrm{L}$ & 60 & 80 \\
\hline 36 & GM & $P$ & 60 & 75 \\
\hline 37 & HA & $P$ & 45 & 70 \\
\hline 38 & $\mathrm{HH}$ & $\mathrm{L}$ & 50 & 75 \\
\hline 39 & $\mathrm{IH}$ & L & 50 & 75 \\
\hline 40 & KP & $\mathrm{P}$ & 55 & 70 \\
\hline 41 & $\mathrm{KM}$ & $\mathrm{L}$ & 50 & 65 \\
\hline 42 & SA & $P$ & 60 & 80 \\
\hline
\end{tabular}




\begin{tabular}{|c|c|c|c|c|}
\hline 43 & MAA & P & 65 & 75 \\
\hline 44 & MFB & L & 40 & 55 \\
\hline 45 & NA & $P$ & 65 & 50 \\
\hline 46 & NPB & $\mathrm{P}$ & 45 & 80 \\
\hline 47 & RPM & $\mathrm{L}$ & 50 & 65 \\
\hline 48 & $\mathrm{~S}$ & $P$ & 65 & 75 \\
\hline 49 & TAA & $\mathrm{P}$ & 60 & 70 \\
\hline 50 & $\mathrm{TQ}$ & $P$ & 65 & 65 \\
\hline 51 & YA & $\mathrm{L}$ & 40 & 65 \\
\hline \multicolumn{3}{|c|}{ Jumlah Siswa $\left(\sum n\right)=51$} & Jumlah nilai $\left(\sum X\right)=2850$ & $\begin{array}{c}\text { Jumlah nilai }\left(\sum X\right)= \\
3575\end{array}$ \\
\hline \multicolumn{3}{|c|}{$\begin{array}{c}\text { Rata-rata nilai }(\bar{X})= \\
\frac{\sum X}{\sum n}\end{array}$} & $\begin{aligned} \bar{X} & =\frac{2850}{51} \\
& =55.88\end{aligned}$ & 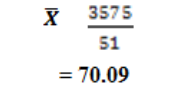 \\
\hline
\end{tabular}

\section{Skor Hasil Pre Test dan Post Test Pembelajaran IOC Kosakata}

Berdasarkan tabel di atas yang diperoleh selama pelaksanaan menunjukan bahwa skor para siswa pada pre tes rendah. Hal ini dikarenakan keaktifan siswa dalam pembelajaran kosakata masih rendah, dan juga informasi awal tidak ada maka dalam pembelajaran siswa cenderung pasif.

Agar kualitas pembelajaran kosakata bahasa Inggris tingkat dasar meningkat, maka perlu adanya model pembelajaran yang dapat memperbaiki skor para siswa tersebut. Hal yang sudah dilakukan antara lain; (1) membuat students' notebook, (2) menyiapkan rencana atau rancangan pembelajaran menggunakan model pembelajaran inside-outside circle dengan memperhatikan pembagian waktu yang sebaik-baiknya, (3) menambahkan waktu dalam pelaksanaan IOC, dan (4) mempersiapkan ulang lembar observasi pengelolaan pembelajaran guru, lembar observasi aktivitas siswa, dan lembar catatan lapangan.

Students' notebook pada kegiatan ini bertujuan agar para siswa mendapatkan informasi berdasarkan apa yang dipelajari pada masing-masing tema kosakata, dan mereka membuat catatan kosakata bahasa Inggris dengan menuliskannya sendiri di media yang sudah disiapkan oleh tim. Dalam pengisian dan mencatat kosakata dalam notebook tersebut juga dipandu oleh kedua tim. Kedua, penambahan waktu dalam pergerakan lingkaran luar dan dalam. Penambahan waktu ini menjadikan siswa dalam mengumpulkan informasi tentang daftar kosakata bahasa Inggris dasar yang harus dicatat dan dikuasai. Ketiga, dalam melakukan pembelajaran kosakata bahasa Inggris tingkat dasar ini, tentunya tim memperhatikan tahap-tahap pembelajaran yang sudah direncanakan agar IOC berjalan dengan baik dan tidak ada kegiatan pembelajaran yang terlewati.

Dari skor hasil pre tes dengan skor post tes, nilai rata-rata siswa pada pre tes yaitu sebesar 55.88, sedangkan setelah dilakukan penerapan model belajar koperatif IOC dalam usaha perbaikan tahap sebelumnya, nilai rata-rata siswa meningkat menjadi 70.09.

Model pembelajaran insideoutside circle ini menjadikan aktivitas siswa meningkat. Keaktifan para siswa tampak pada keaktifan menjawab dan bertanya siswa. Keaktifan siswa ini disebabkan oleh adanya penerimaan informasi yang sama pada masingmasing siswa. Dari penerimaan informasi yang sama ini siswa menjadi aktif bertanya dan menjawab, hal ini dikarenakan siswa sudah mengerti hal yang dibahas dalam proses pembelajaran kosakata bahasa Inggris tingkat dasar.

Model pembelajaran IOC dapat meningkatkan kualitas pembelajaran kosakata bahasa Inggris dasar dengan berbagai tema. Peningkatan ini disebabkan oleh adanya peningkatan aktivitas belajar siswa yang tercipta dengan adanya interaksi positif antara siswa dengan siswa lainnya. Setiap siswa menyampaikan hasil catatan daftar kosakata yang dituliskannya sendiri dalam notebook yang diperdengarkan dengan siswa lain. Dengan model pembelajaran IOC siswa dapat mengetahui langsung interpretasi siswa lain sehingga dapat mempermudah 
dalam mengetahui, menghafal, dan merelevansinya. Proses ini sesuai dengan pendapat Suprijono (2011:54) untuk mencapai hasil pembelajaran yang maksimal, harus ada lima unsur pokok yang diterapkan, yaitu saling ketergantungan positif, tanggung jawab perorangan, interaksi promotif, komunikasi antar siswa, dan proses kelompok.

Pembelajaran yang dilakukan dalam kegiatan ini berpusat pada siswa sehingga siswa bukanlah objek pembelajaran saja, namun juga sebagai subjek pembelajaran. Hal ini dilakukan dengan tujuan agar perhatian dan konsentrasi siswa lebih terbangun. Guru memposisikan diri sebagai fasilitator dalam memberikan pemahaman terhadap materi pembelajaran pada khususnya dan keseluruhan kegiatan pembelajaran pada umumnya. Pemberian materi tidak dilakukan dengan cara konvensional, guru lebih menekankan keterlibatan siswa dalam pembelajaran sehingga perhatian dan konsentrasi siswa dapat meningkat.

Penerapan model pembelajaran IOC terbukti dapat meningkatkan perhatian dan konsentrasi siswa. Seperti yang dikemukakan Dimyati dan Mudjiono (2006:4) belajar merupakan pengalaman yang diperoleh dari lingkungan. Pengalaman pada dasarnya adalah hasil dari interaksi antara siswa dengan lingkungannya. Menghadirkan nuansa pembelajaran yang menarik dapat meningkatkan hasil belajar siswa. Pembelajaran kooperatif model IOC merupakan salah satu jenis pembelajaran kooperatif yang cukup menarik untuk diterapkan (Suprijono, 2011:97). Lebih lanjut Isjoni (2011:61) menyatakan bahwa menciptakan lingkungan kelas yang menarik maka dapat memudahkan siswa dalam memahami materi.

Model pembelajaran kooperatif IOC mampu meningkatkan interaksi siswa dengan siswa dan siswa dengan guru sehingga siswa dapat meningkatkan hasil belajarnya. Kegiatan pembelajaran dengan penerapan model pembelajaran koperatif ini telah membuktikan bahwa penerapan model IOC atau lingkaran besar lingkaran kecil mampu meningkat hasil belajar kosakta bahasa Inggris pada tingkat dasar di MI Miftahul Jannah.

\section{PENUTUP}

Berdasarkan hasil yang diperoleh para siswa saat pre test dan post test, maka model pembelajaran Inside Outside Circle ini dapat dijadikan alternatif bagi guru untuk meningkatkan kosakata para siswa di tingkat dasar, sehingga, para siswa memiliki pondasi yang kuat dalam mempelajari mata pelajaran bahasa Inggris dengan baik dan benar, serta mampu mengaplikasikannya dalam sebuah interaksi dan percakapan sehari-hari yang bersifat dinamis dan sistematis sesuai dengan konteks situasi. Diharapkan, apabila para siswa menguasai kosakata bahasa Inggris dari dasar, secara otomatis para siswa akan lebih mudah nantinya mempelajari bahasa Inggris pada tingkat selanjutnya.

\section{DAFTAR PUSTAKA}

Azhari, M.A. Yusuf Ali., Suwignyo, Heri., Hasanah, Muakibatul. 2013. Penerapan Pembelajaran Koperatif Model Inside Outside Circle untuk Meningkatkan Hasil belajar Apresisi Dongeng Siswa Kelas VIIC MTsN Ngronggtot Nganjuk. Malang: Universitas Negeri Malang.

Dimyati \& Mudjiono. 2006. Belajar dan Pembelajaran. Jakarta: Rineka Cipta. 
Gavruseva, Haznedar, B.E. (2008). Current Trend in Child Second Language Acquisition. Philadelphia: John Benjamin Publishing Company.

Isjoni. 2009. Cooperative Learning. Bandung: Alfabeta.

Lie, Anita. 2007. Cooperative Learning. Jakarta: PT Gramedia. Cet. Ke-5. 2008. Cooperative Learning: Mempraktikkan Cooperative Learning Di Ruang-ruang Kelas, Jakarta: Grasindo.
Maufur, Hasan Fauzi. 2009. Sejuta Jurus Mengajar Mengasyikkan, (Semarang: PT. Sindur Press.

Moon, Jayne. 2000. Children Learning English. Oxford: Macmillan Publishers Limited.

Suprijono, Agus. 2011. Model-Model Pembelajaran. Jakarta: Gramedia Pustaka Jaya.

Sugiyanto.2010. Model-Model Pembelajaran Inovatif. Surakarta: Yuma Pustaka. 